\title{
The Academic Achievement and Attainment of LGB America
}

\author{
Joel Mittleman \\ Assistant Professor, University of Notre Dame
}

\begin{abstract}
The current study provides large-scale, replicated evidence on the academic achievement and attainment of America's lesbian, gay and bisexual population. I use a total of eight waves from two nationally representative surveys of American adults - the National Health Interview Survey $(N=145,941)$ and the National Survey of Drug Use and Health $(\mathrm{N}=96,073)$ - alongside restricteduse data from the High School Longitudinal Study of $2009(\mathrm{~N} \approx 15,870)$ - the first such study to ever collect information on student sexual orientation. Across datasets and birth cohorts, gay men display a pattern of strikingly high achievement: their rates of BA attainment are not only higher than straight men's, they are also higher than straight women's. Gay men's academic success is observable already by ninth grade. Compared to straight boys in the same school, gay boys perform better on a range of attitudinal, behavioral, and achievement outcomes. Sensitivity analyses suggest that this pattern is unlikely to be explained by selective disclosure of a gay identity. By contrast, lesbian women's BA attainment has declined across birth cohorts, such that lesbian women are now broadly disadvantaged compared to straight women. Although bisexuals in recent cohorts report academic disadvantages, substantial variation in reported rates of bisexual identity across sexes, cohorts and datasets complicates the interpretation of these results.
\end{abstract}

\section{Background:}

In its landmark report LGBTQ Issues in Education: Advancing a Research Agenda, the American Education Research Association noted that "there is limited education research with representative samples of LGBTQ students" because data limitations have long made it “impossible to link LGBTQ status with students' educational outcomes" (Wimberly 2015: 195196). Instead, research on America's sexual minority population has typically analyzed schools primarily as sites of victimization (e.g., Toomey and Russell 2016) or as contexts that contribute to health disparities (e.g., Hatzenbuehler and Keyes 2013; Hatzenbuehler et al. 2014). The Add Health Study enabled a generation of education research on sexual minorities (e.g., Russell, Seif, and Truong 2001; Pearson, Muller, and Wilkinson 2007; Mollborn and Everett 2015). However, these studies document the experiences of just one cohort, whose high school careers culminated nearly twenty years ago. As recent reviews argue (e.g., Wimberly 2015; Pearson and Wilkinson 2018), there is a clear need for research that uses large, representative datasets to systematically analyze the academic achievement and attainment of America's LGB population.

The current study addresses this gap by taking advantage of three new data sources to provide replicated evidence on LGB America's core patterns of educational stratification. Using a total of eight waves from two nationally representative surveys of adults, I analyze BA attainment rates by sex, sexual orientation, and birth cohort. Then, using restricted-use data from the High School Longitudinal Study of 2009, I extend the analysis into high school, documenting disparities on a variety of academic, attitudinal and behavioral outcomes. 


\section{Data:}

To identify large, nationally representative samples of LGB adults, the current study takes advantage of two population health surveys: the National Health Interview Survey (NHIS) and the National Survey of Drug Use and Health (NSDUH). Funded through the Centers for Disease Control and Prevention, both of these household surveys are conducted annually and in person. Since 2013 and 2015, respectively, the NHIS and NSDUH have collected information on sampled adults' $(18+)$ sexual orientation. Each survey also asks about respondents' level of educational attainment. To allow respondents roughly six years to complete college, I restrict the sample to adults aged 24 or older. Pooling across all available waves of each survey, I produce an NHIS sample of 142,366, 2,466, and 1,109 straight, gay/lesbian and bisexual respondents, respectively, and an NSDUH sample of 91,075, 1,947, 3,051 such respondents.

Given their size and independent data collection efforts, replicated results across the NHIS and NSDUH provide compelling evidence on the patterns of BA attainment among LGB adults. Neither dataset, however, includes further information on respondents' school-related experiences and outcomes. Therefore, I complement these surveys with newly released, restricted-use data from the High School Longitudinal Survey of 2009 (HSLS:09). The HSLS:09 is the fifth in a series of high school cohort studies that, since the 1970's, have been central to sociological research on education generally (e.g., Brint 2013) and on gender patterns in education specifically (e.g., Buchmann and DiPrete 2006). Conducted by the U.S. Department of Education, the HSLS:09 has followed a nationally representative sample of ninth grade students through four waves of data collection. The latest wave, administered in 2016, assesses students' postsecondary enrollment and — for the first time in these studies—students' sexual orientation.

\section{Results:}

Figure 1 presents the reported rates of gay, lesbian and bisexual identities in the NHIS NSDUH, and HSLS:09, separately by sex and birth cohort. Notably, rates of gay and lesbian identities are fairly consistent across datasets, sexes, and cohorts. By contrast, and consistent with other research (England, Mishel and Caudillo 2016), rates of reported bisexual identity have increased dramatically among women in recent birth cohorts.

\section{[ Figure 1]}

Figure 2 presents rates of BA attainment for straight, gay/lesbian and bisexual American adults. These average adjusted predictions are based on linear probability models controlling for race/ethnicity, nativity and age last birthday; unadjusted results are substantively identical. Across datasets, gay and lesbian respondents have higher rates of BA attainment than straight respondents. Overall, bisexuals are roughly at parity with straight respondents, with some slight apparent advantages among men and disadvantages among women.

\section{[ Figure 2]}

These overall comparisons between sexual orientation groups mask significant heterogeneity by birth cohort. Figure 3 presents the average adjusted predictions from models of the three-way interaction between sex, sexual orientation and birth cohort, controlling for the same covariates as above. For visual clarity, these figures exclude bisexuals; results including bisexuals are provided in Appendix Figure 1A.

[ Figure 3 ] 
Across both datasets and all cohorts, gay men have higher rates of BA attainment than both straight men and straight women. In both datasets, lesbian women born before 1960 had higher rates of BA attainment than straight men and women, but this advantage had declined into a slight disadvantage by the most recent cohort (with conflicting results for the middle cohort).

Figure 4 presents BA attainment rates for the post-1980 birth cohort alongside the BA enrollment rates for the HSLS:09 cohort (which was born, on average, in 1995). The figure underscores the consistency of results across datasets. In every dataset, gay men have the highest rates of any group. The figure also reveals the consistent disadvantages among bisexuals, particularly bisexual women. Lesbian women consistently have higher BA attainment/enrollment rates than bisexual women but lower rates than straight women (though the magnitude and significance of lesbian-straight disparities varies by dataset).

\section{[ Figure 4]}

Does this pattern of gay men's academic advantage and lesbian women's disadvantages extend to other high school outcomes? Figure 5 addresses this question, presenting estimates from school fixed effects models, controlling for students' race/ethnicity, nativity and parent socioeconomic status. Compared to straight boys in the same high school, gay boys were significantly more successful across a full range of outcomes. According to their high school transcripts, gay boys had better final GPA's and higher rates of honors classes. Already in 9th grade, gay boys had better grades, reported better work habits (e.g., going to class with homework done), were more likely to endorse pro-school attitudes, and reported significantly higher postsecondary expectations. Lesbian girls' disadvantages were less consistent. They had lower GPA's than straight girls - both overall and in 9th grade - and had lower postsecondary expectations. However, none of the other lesbian-straight disparities were statistically significant or substantively meaningful. Bisexual-straight disparities on these outcomes, not shown, are inconsistent for boys but consistently negative for girls.

\section{[ Figure 5]}

\section{Sensitivity Tests:}

Across all results, the most striking pattern is the high achievement reported by gay men. Could this pattern be driven by selective disclosure of gay identity? One could imagine that perhaps only the most educationally successful gay men are willing to report a gay identity, even on an anonymous survey. Notably, this pattern of education-related selective disclosure would have to apply only to gay men: if it were only the educationally successful who came out, in general, then we would expect artificially positive outcomes across all sex-sexual orientation groups. Still, one might be concerned that there is gay male specific barrier to disclosing a sexual minority identity. To explore this, I present three forms of evidence from the HSLS:09.

First, in Figure 6, I chart the percentage of men reporting a gay identity across a variety of family and contextual characteristics. If selective disclosure of gay identities were to be a potentially significant issue in the data, then we would expect noticeable variability across groups. Instead, the figure illustrates that gay reporting rates are remarkably consistent across a number of groups, including groups that one might expect would be associated with lower rates of reporting. The consistency of reporting across groups provides initial evidence against the concern that selective disclosure is producing gay men's apparent advantages. 
[Figure 6]

A second kind of evidence is presented in Figure 7. Other research on contemporary gay young adults establishes that this population faces elevated rates of psychosocial vulnerabilities on measures such as depression/anxiety and perceived discrimination (e.g., Meyer 2016). If these same disparities were not present in the HSLS:09, then one might imagine that only the most broadly advantaged gay men were disclosing their identities. Figure 7 demonstrates that this is not the case. On four psychosocial measures reported by respondents in the most recent wave of data collection, gay men reported significantly worse outcomes than their straight schoolmates. Indeed, the disparities reported by gay men are similar in magnitude to those reported by lesbian women, despite their very different educational outcomes. The academic advantages reported by gay men appear to be domain-specific, not reflective of a broader pattern of advantage.

[Figure 7]

Finally, perhaps the strongest evidence against the concern that gay men's academic advantages are the result of unmeasured selection into disclosing a gay identity is shown in Figure 8. In the HSLS:09, respondents were asked about their sexual orientation in the most recent wave of data collection, when respondents were in college. One might imagine that fouryear, BA granting institutions are social contexts that would enable individuals to explore and embrace their sexual orientation. If this is true, then the elevated rates of BA enrollment among gay men could be driven by the fact that college-enrolled gay men are the most willing to report their identity. Positive outcomes observed in high school, therefore, could be the result of selecting on the dependent variable: identifying only the eventual academic successes.

One way to assess this possibility is to explore high school outcomes only among those who never went on to enroll in a four-year college. If gay men still have an advantage even among those who didn't make it to college, then that is strong evidence for a genuine gay advantage. Figure 8 shows that is precisely the case. Although gay men's advantages are attenuated on some outcomes - particularly final and 9 th grade GPA — gay students still consistently outperformed their straight schoolmates on every outcome considered.

[Figure 8]

Given these three sensitivity tests, I argue that gay men's academic advantages are unlikely to be explained only by selective disclosure of gay identity.

\section{Discussion:}

Across three datasets, the current study provides largely consistent evidence on the patterns of academic achievement and attainment of America's LGB population. By most every measure, gay men display strikingly high levels of academic achievement. In birth cohorts for which college completion was uncommon for women, lesbian women had relatively levels of BA attainment. Among more contemporary cohorts, however, lesbian women face slight, although inconsistent, disadvantages. The patterns observed among the bisexual population are more varied and difficult to reliably interpret, given substantially different rates of bisexual identity reported across datasets, cohorts, and sexes. 
Figure 1
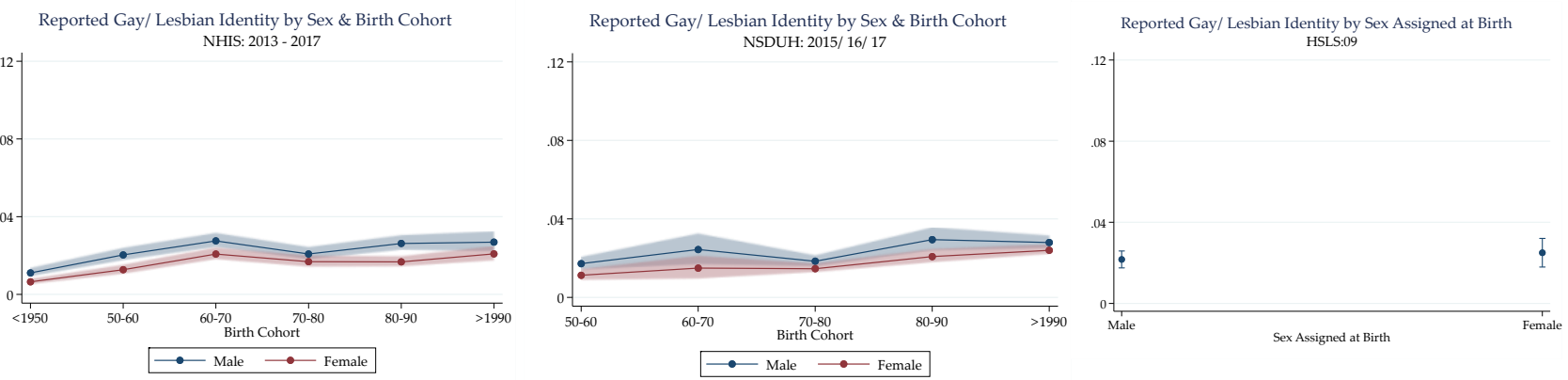

Reported Bisexual Identity by Sex \& Birth Cohort
NHIS: 2013 - 2017
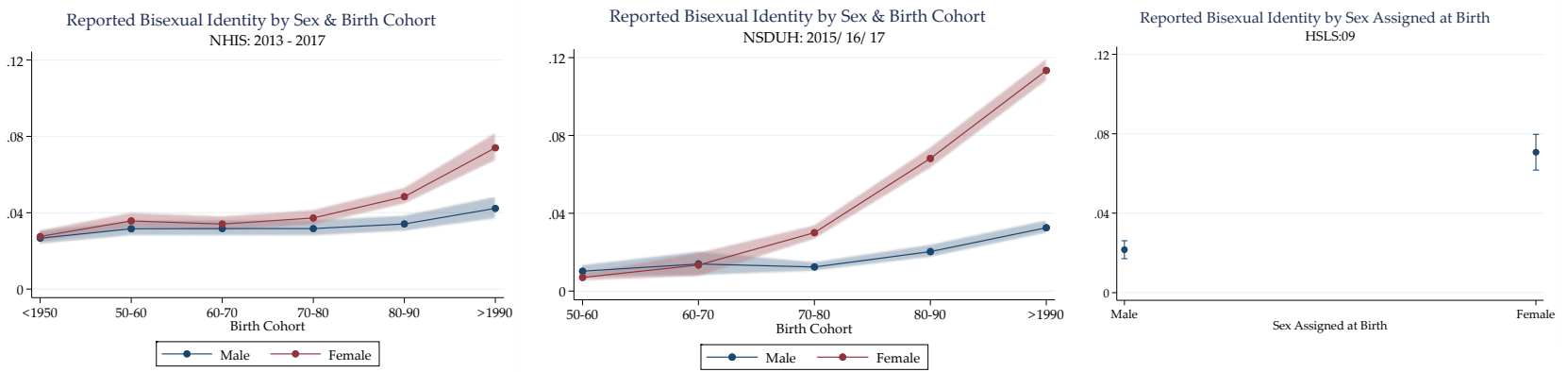

\section{Figure 2}
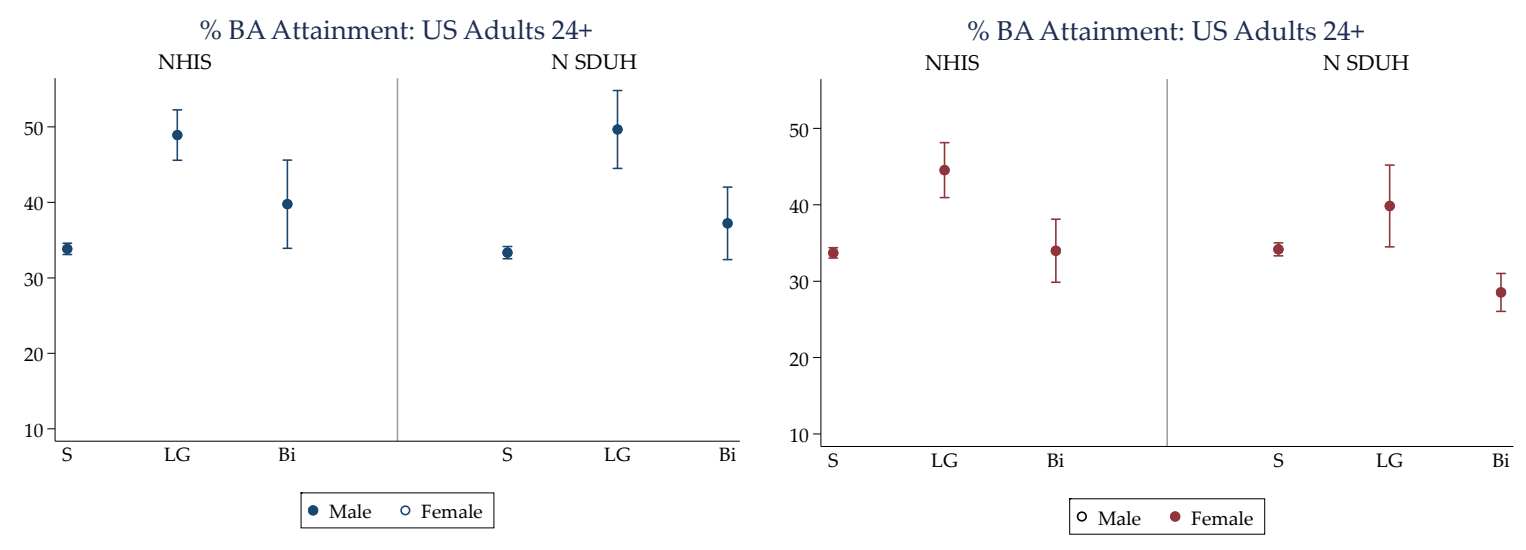


\section{Figure 3}

BA Attainment by Sex and Birth Cohort NHIS: 2013 - 2017

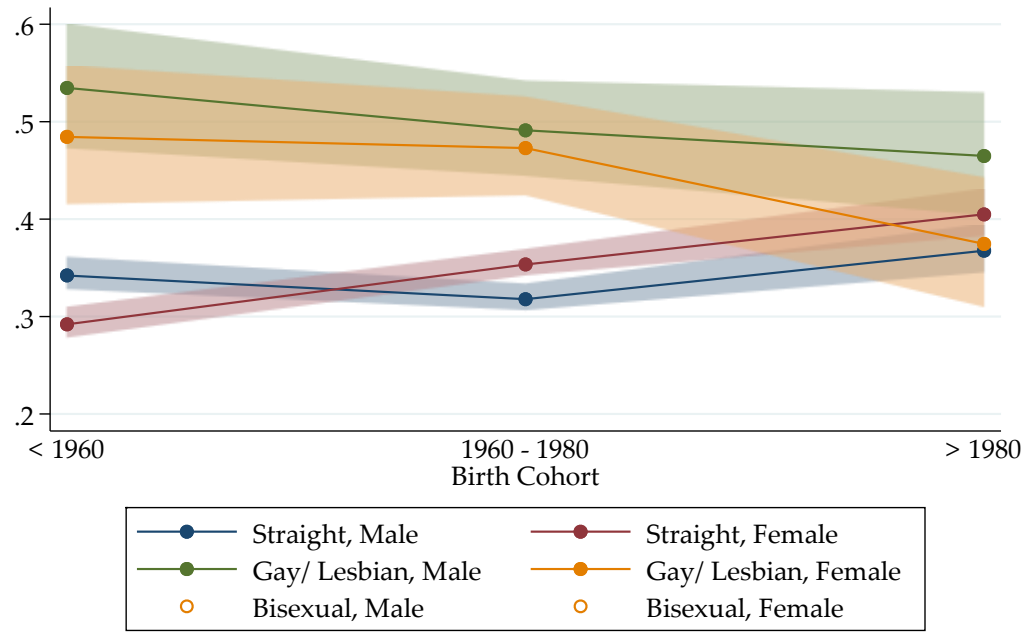

BA Attainment by Sex and Birth Cohort NSDUH: 201520162017

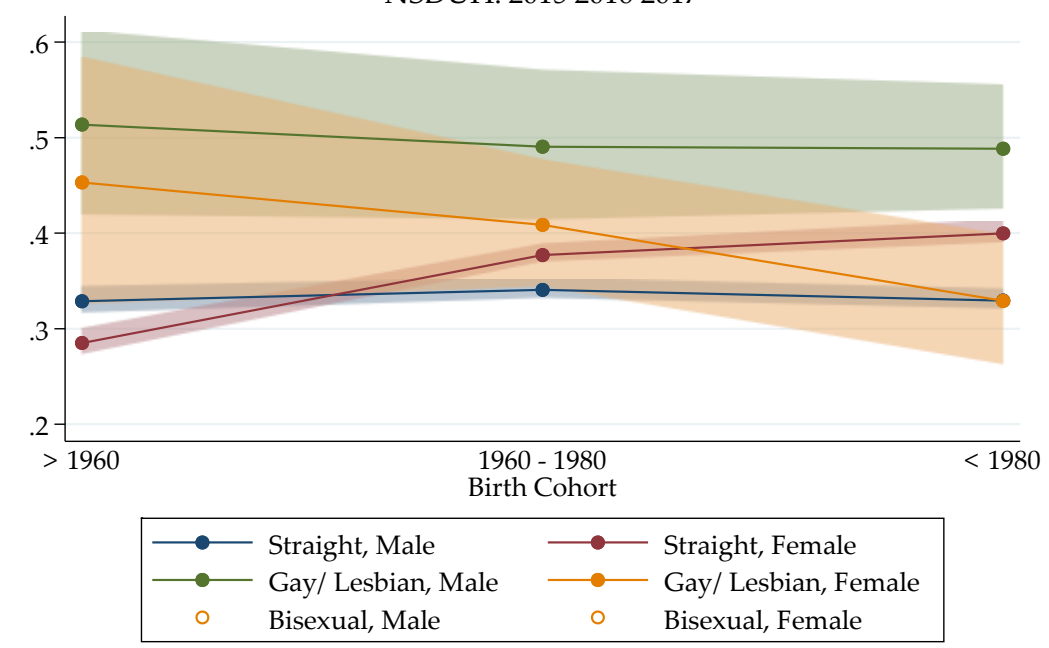

Figure 4

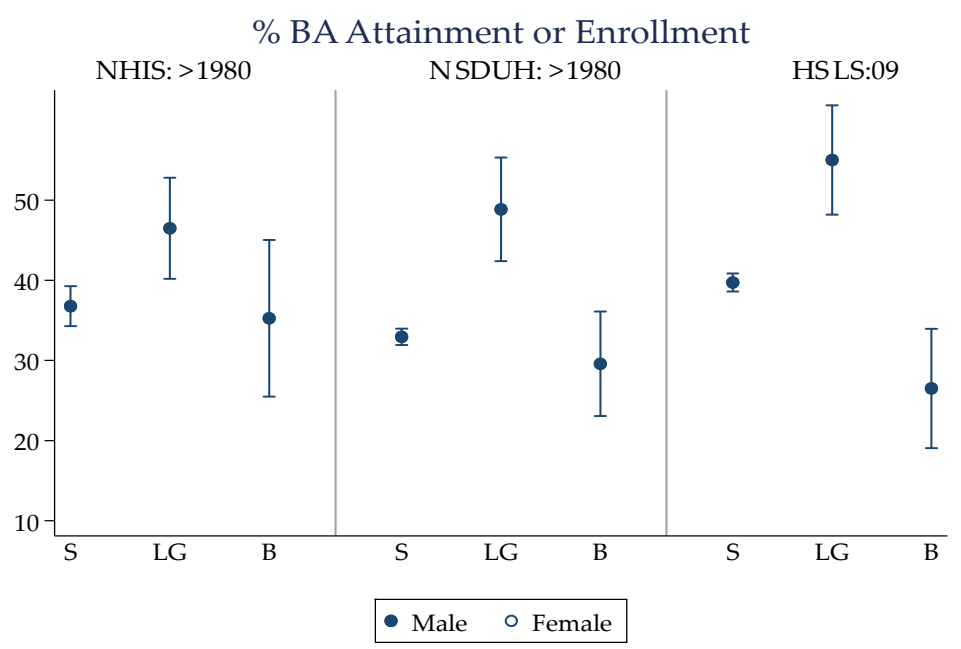

\% BA Attainment or Enrollment

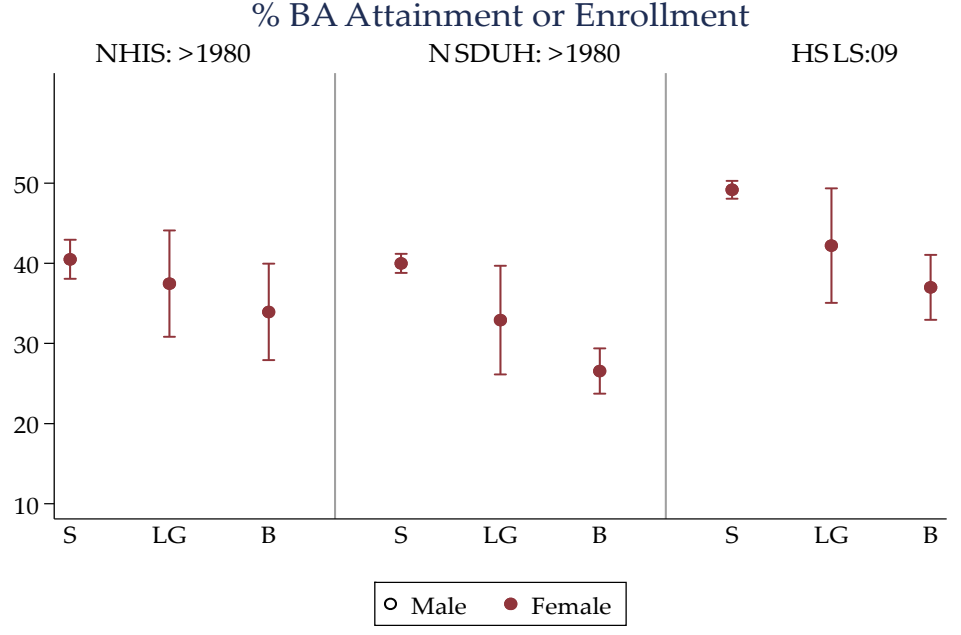




\section{Figure 5}

HSLS: Gay and Lesbian Academic (Dis)Advantages:

Other Academic Outcomes

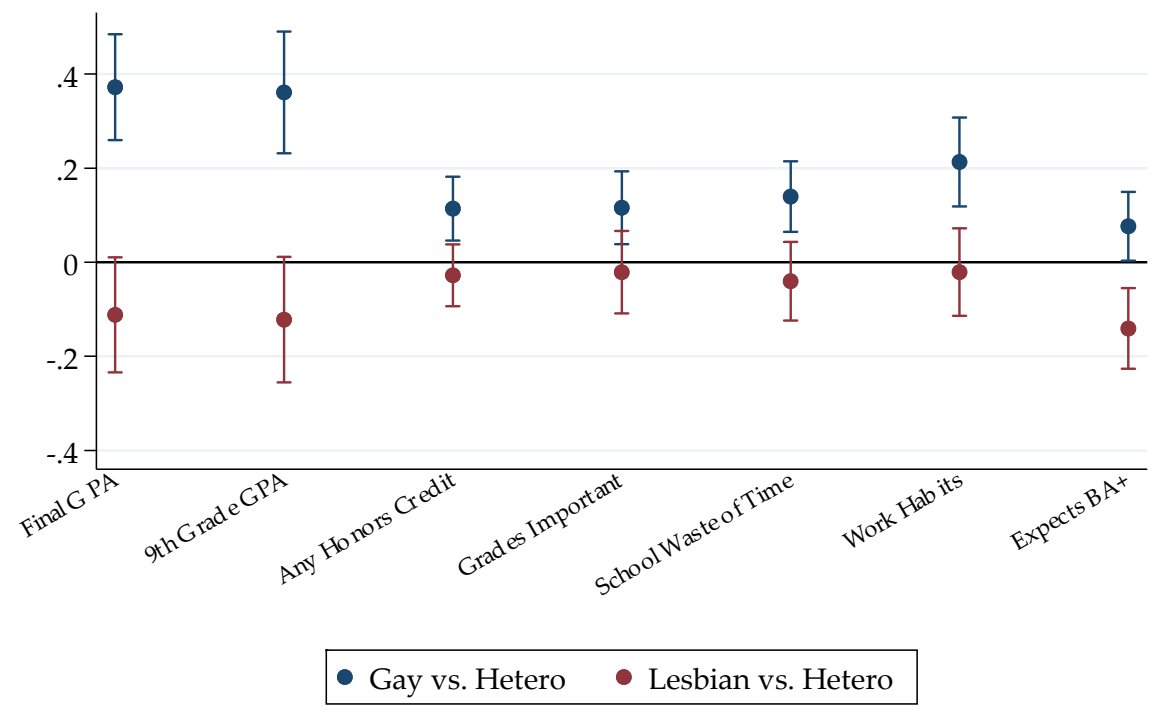

Figure 6

Percent Reporting Gay Identity: HSLS By Family Background Characteristics

Percent Reporting Gay Identity: HSLS By High School Context

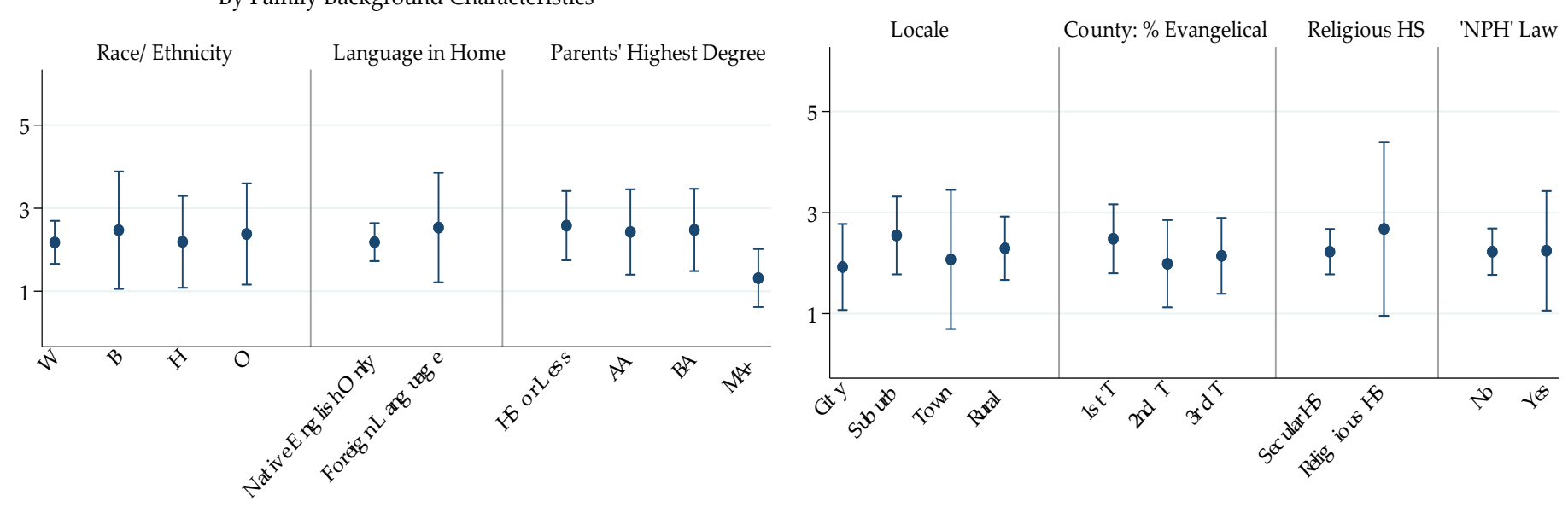


Figure 7

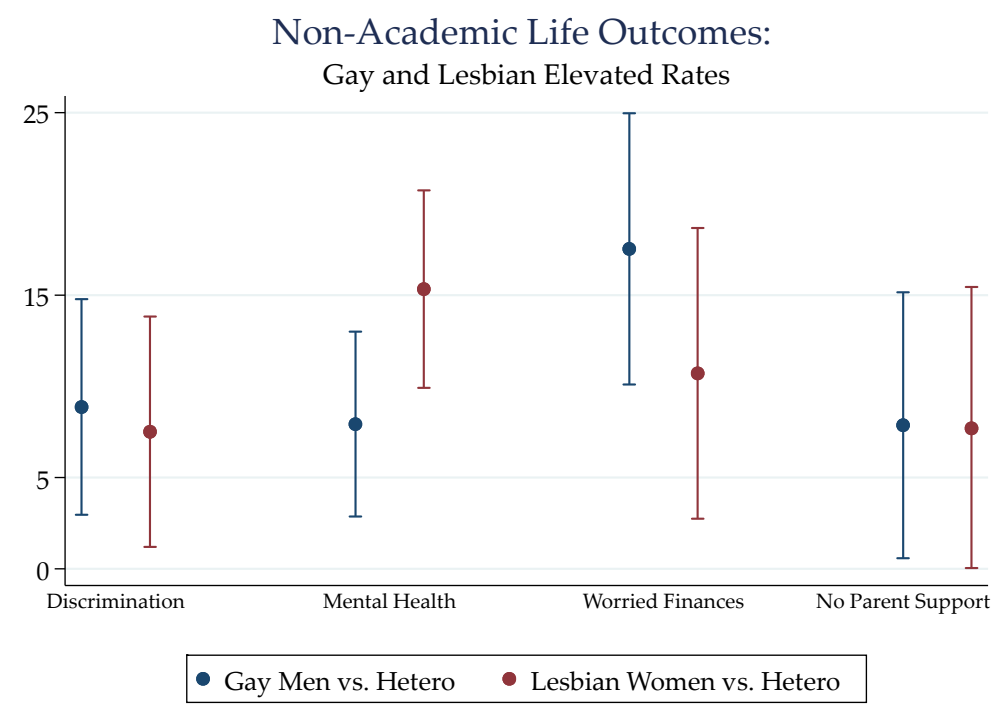

Figure 8

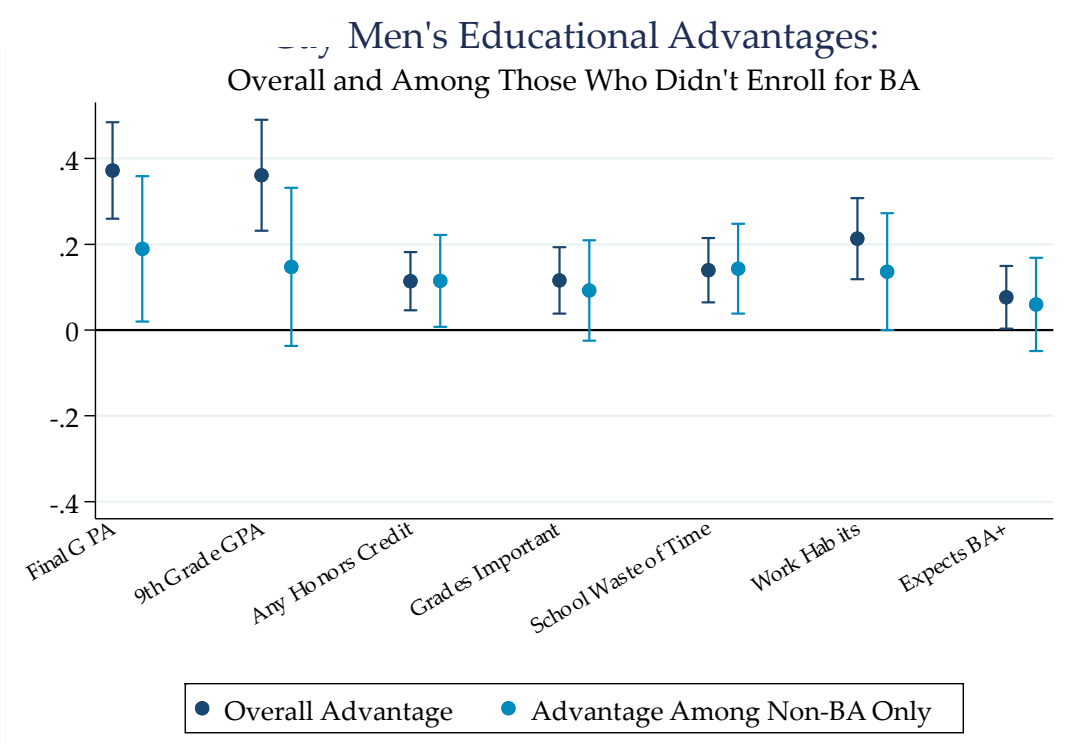




\section{Appendix Figure 1A}
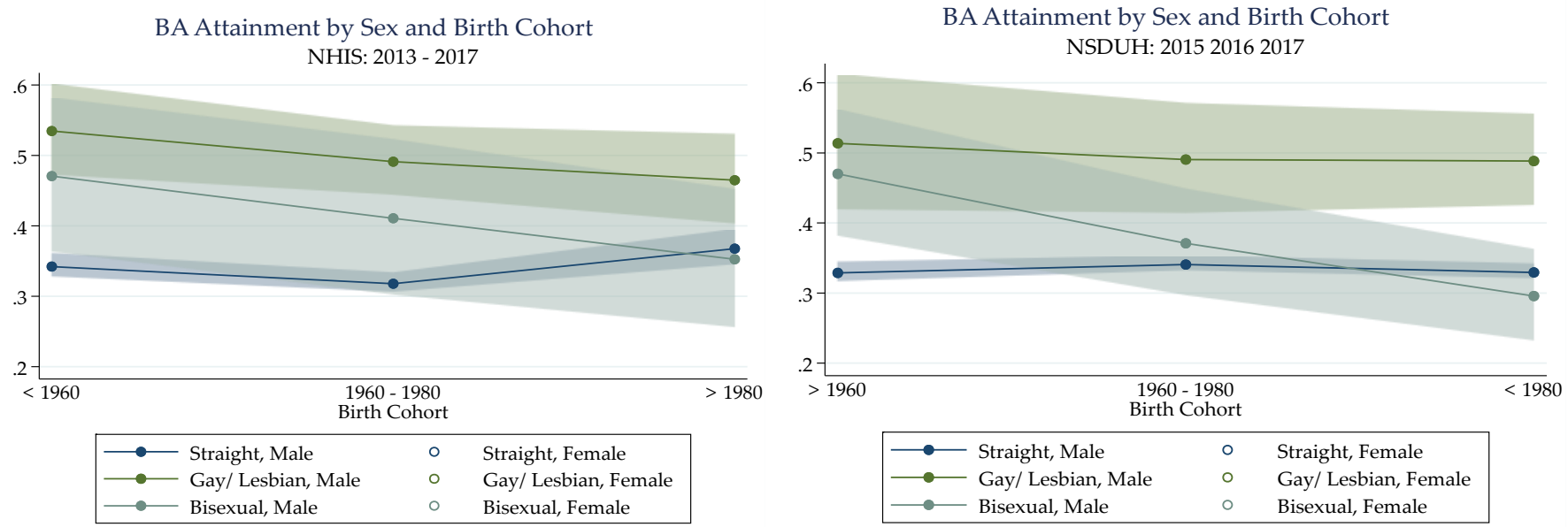

BA Attainment by Sex and Birth Cohort NHIS: 2013 - 2017

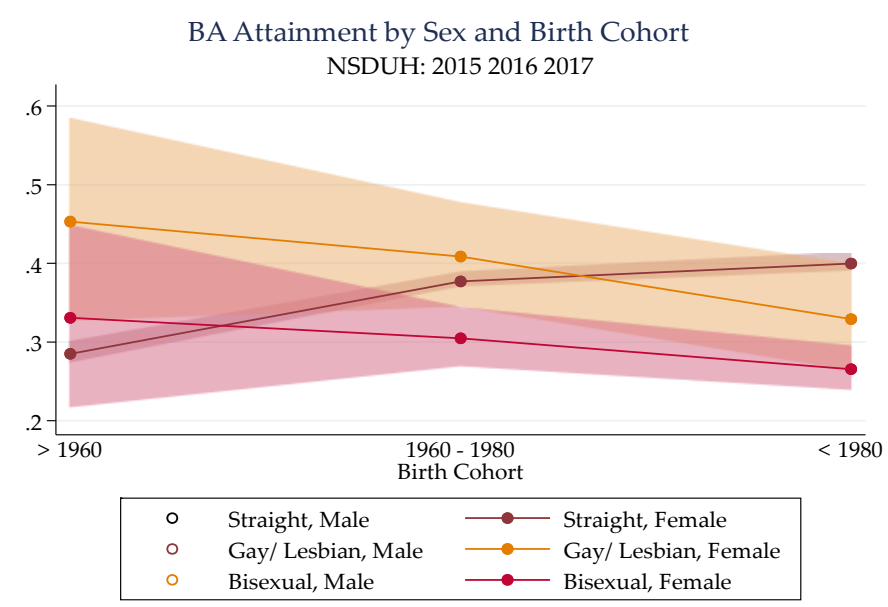

